\title{
A influência da religiosidade no conviver com o HIV
}

\author{
Débora Carvalho Ferreira ${ }^{1}$ \\ Cesar Augusto Orazem Favoreto \\ Maria Beatriz Lisbôa Guimarães ${ }^{3}$
}

FERREIRA, D.C.; FAVORETO, C.A.O.; GUIMARÃES, M.B.L. The influence of religiousness on living with HIV. Interface - Comunic., Saude, Educ., v.16, n.41, p.383-93, abr./jun. 2012.

The correlation between health and spirituality within the field of chronic illness is assessed, with a view to understanding how individuals seek support to strengthen themselves against the adversities imposed by the disease. Qualitative methodology was used to discuss issues relating to religiousness that emerged in the words used by people living with HIV. Based on their narratives, reports on religiousness and its influence on the health-disease process were analyzed thematically. Some relationships pointing towards positive and/or negative religious ways of coping with the disease, changes in religious thought and behavior, and the importance of religious experience on how individuals develop their narratives of illness, were observed. Attention was drawn to the need for healthcare professionals to be aware of the emergence of such content, since this brings out factors involved in therapeutic issues, like compliance, social support, conflicts and individuality, which may help them in coping with the disease.

Keywords: Chronic illness. HIV. Religion. Narrative.
Abordam-se as correlações entre saúde e espiritualidade, no campo do adoecimento crônico, visando compreender como os indivíduos buscam subsídios para se fortalecer diante das adversidades impostas pela doença. Emprega-se metodologia qualitativa para se discutirem questões sobre religiosidade que emergiram na fala de pessoas que convivem com o HIV. Com base na narrativa desses sujeitos, foram analisados o relato sobre religiosidade e suas influências no processo saúde-adoecimento, realizando uma análise temática. Foram observadas algumas relações que apontam para: enfrentamentos religiosos positivos e/ou negativos no adoecimento, mudanças de pensamento e comportamentos religiosos, assim como a importância da vivência religiosa na maneira como os indivíduos elaboram suas narrativas de adoecimento. Chama-se atenção para a necessidade de os profissionais de saúde estarem atentos ao surgimento de tais conteúdos, pois trazem aspectos que envolvem questões terapêuticas - como adesão, apoio social, conflitos e singularidades individuais que podem auxiliar no enfrentamento da doença.

Palavras-chave: Doença crônica. HIV. Religião. Narrativa.

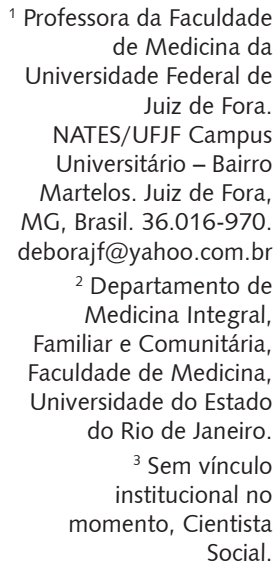

${ }^{1}$ Professora da Faculdade de Medicina da Universidade Federal de Juiz de Fora.

NATES/UFJF Campus Universitário - Bairro Martelos. Juiz de Fora, MG, Brasil. 36.016-970. deborajf@yahoo.com.br

${ }^{2}$ Departamento de Medicina Integral, Familiar e Comunitária, Faculdade de Medicina, Universidade do Estado do Rio de Janeiro.

${ }^{3}$ Sem vínculo institucional no momento, Cientista Social. 


\section{Introdução}

A ligação entre religiosidade e saúde tem sido foco de alguns estudos que apontam para uma relação de melhora nos índices de saúde e bem-estar entre pessoas que se consideram religiosas (Ayle et al., 1999; Ellison, 1991; Ferraro, 1991). Levin e Schiller (987) foram os primeiros pesquisadores a discutirem esta questão, num enfoque epidemiológico, ao identificarem que vivências religiosas e espirituais tinham correlação significativamente positiva sobre taxa de saúde e doença. Após a década de 80 do século passado, vem crescendo a discussão científica sobre tal ligação, inclusive no Brasil (Vasconcelos, 2006).

Em revisão da literatura recente, Guimarães e Avezum (2007) estudaram 242 artigos que tinham como tema a ligação da religiosidade/espiritualidade com a saúde, e descrevem resultados positivos na redução de mortalidade em geral, assim como nas áreas de imunologia, saúde mental, doenças cardiovasculares e neoplasias. Tais resultados apontam para a necessidade de se aprofundar cada vez mais este tema, que já foi tão incerto para a ciência, mas que agora começa a participar dela.

As correlações positivas entre saúde e espiritualidade estão significativamente ligadas às doenças crônicas (Bussing et al., 2009; Peres et al., 2007), posto que constituem subsídios que as pessoas buscam para se fortalecerem diante das adversidades impostas pela condição patológica (Freitas, Mendes, 2007). Dentro desse universo, o adoecimento pelo HIV é colocado em destaque, devido a sua característica peculiar de ser uma doença infectocontagiosa que, no momento atual do desenvolvimento científico, se configura como uma doença crônica (Schaurick et al., 2006), além de carregar um histórico de agregação de valores sociais e morais que abarcam, inclusive, questões religiosas (Daniel, Parker, 1990).

Assim, a Aids, que já foi rótulo de morte preditada (Daniel, Parker, 1990), hoje convive com os problemas próprios das doenças crônicas, como: cuidados continuados (Silva, 2004; Paiva, 2002), adesão terapêutica (Silva et al., 2009; Melchior, 2007; Schaurick et al., 2006;) e integralidade na atenção (Cunha, Czeresnia, 2005; Silva et al., 2005). Porém, é inegável que, além disso, ainda carrega um rol de preconceitos grandes, o que faz com que tal doença tenha significados e olhares particulares para todos os indivíduos que convivem com ela (Brien et al., 2008).

$\mathrm{Na}$ busca desse olhar que procura o entendimento da vivência dos indivíduos, muito tem sido produzido no campo dos estudos qualitativos que abordam o (con)viver com o HIV, e que vão além das questões relativas aos impactos físicos da doença. Muitos pesquisadores procuram entender o universo de símbolos e significados que permeiam este processo, para assim melhor promoverem cuidados para as pessoas que convivem com o vírus (Favoreto, Ferreira, 2009; Silva, 2004).

Neste trabalho parte-se de um estudo qualitativo exploratório sobre os significados de conviver com a infecção pelo HIV, com as situações de adoecimento dela decorrentes e com a adesão aos tratamentos antirretrovirais. As falas das pessoas entrevistadas apontam que elas constroem seus modos narrativos para explicar para si mesmas a história de seu contágio por HIV, assim como para elaborar seus modos de enfrentamentos permeados por atitudes de protagonismo e autonomia (Favoreto, Ferreira, 2009).

Foram observadas nessa pesquisa rupturas sociais e morais causadas pela infecção - e, também, pelo tratamento, que apontam para o papel de protagonismo dos indivíduos em relação a sua história, agenciando uma experiência de autocuidado que leva à adesão terapêutica. Porém, emergiram também, nas falas dos sujeitos, de maneira espontânea, questões ligadas às suas relações com religião e espiritualidade. A dimensão espiritual esteve presente nas construções de significados, integrados nos modelos explicativos do adoecer e às formas de enfrentamento da doença. Esta dimensão perpassa as construções de significados e vivências que se mostram relevantes nas histórias narradas (Favoreto, Ferreira, 2009).

Diante da emergência da temática da religiosidade nas falas dos sujeitos e de um aprofundamento no interesse dos autores por esta temática, optou-se por fazer um recorte dessas narrativas e realizar uma análise mais pertinente ao assunto. Espera-se, desta maneira, complementar a análise dos dados realizada inicialmente. 
Com base em tais colocações, o presente artigo tem como objetivo apresentar os resultados da análise realizada a partir dos relatos das pessoas que convivem com HIV, nos quais emergiram questões relacionadas a religiosidade, procurando interpretar e captar o sentido desses relatos no enfrentamento da doença e suas repercussões sociais, morais e clínicas.

\section{Metodologia}

Este artigo analisa as falas provenientes de entrevistas em profundidade que objetivaram compreender os processos narrativos envolvidos na adesão ao tratamento antirretroviral em portadores do HIV. Ao todo, foram realizadas nove entrevistas, no período de março a junho de 2008, no ambulatório de medicina integral do Hospital Universitário Pedro Ernesto (HUPE) na cidade do Rio de Janeiro. Esta pesquisa foi aprovada pelo CEP desta instituição de acordo com as regras da Lei 196/96.

As entrevistas abordaram os sujeitos quanto aos aspectos relativos à sua vida antes do diagnóstico, no momento do diagnóstico e na fase atual de convivência com a infecção, e a terapêutica utilizada. Transcorriam de modo a deixar os participantes se expressarem livremente, sendo que, em alguns momentos, utilizavam-se questões norteadoras ao tema proposto. Todavia, em relação à religiosidade, não houve, por parte dos entrevistadores, perguntas norteadoras acerca desta temática. Assim, os relatos sobre religiosidade durante a narrativa surgiram espontaneamente e, desta forma, foram analisados, focando as influências no processo saúde-adoecimento, por meio de uma análise temática dos conteúdos contidos nas falas (Minayo, 1994).

As entrevistas foram aplicadas com a preocupação de se escutar e observar a história de vida, adoecimento e terapêutica, de modo que, além dos fatos relatados, fosse possível identificar a forma como a história era narrada. As histórias foram contadas com muita vivacidade e emoção, posto que o entrevistador se colocou no papel de ouvinte atento e interessado. Os diálogos envolveram: as relações entre o contexto socioeconômico e cultural e o adoecimento; as repercussões físicas, morais e sociais da infecção e do tratamento; e as estratégias de enfrentamento, negociação e manejo terapêuticos adotados.

As entrevistas gravadas foram transcritas, e cada fala foi analisada e interpretada como um texto que expõe uma identidade a partir de uma ideologia, e, assim, integra dialeticamente a construção de significados e o modo de organizar objetos e percepções, isto é, a trajetória e os sentidos atribuídos pelas pessoas às suas vivências (Brockmeier, Harré, 2003). Desenvolveu-se, desta maneira, um processo interpretativo que procurou entender o sentido que cada pessoa construiu sobre: a vida com HIV, o adoecimento, a terapêutica e a relação destes aspectos com a religiosidade ou espiritualidade e suas manifestações.

\section{Resultados e discussão}

\section{Apresentação dos sujeitos e suas relações com religião}

${ }^{4}$ Todos os nomes são fictícios.

Carolina 434 anos, natural do Rio de Janeiro, diagnóstico de HIV há nove anos. Relatou ser evangélica neopentecostal praticante.

André: 52 anos, natural do Rio de Janeiro, casado, diagnóstico de HIV há nove anos. Não houve relatos sobre religiosidade em sua fala. 
Rosane: 35 anos, natural do Rio de Janeiro, viúva, mora com a filha. Tem diagnóstico de HIV há nove anos. Não houve relatos sobre religiosidade em sua fala.

Fernando: 46 anos, natural do Maranhão, solteiro, HIV há 13 anos. Relatou ser simpatizante do Espiritismo, porém não frequenta centros ou cultos.

Edivaldo: 39 anos, natural do Rio de Janeiro, HIV há cinco anos. É praticante de Umbanda, como pai-de-santo.

Renato: 45 anos, natural da Bahia, diagnóstico de HIV há seis anos. Referiu ser espírita praticante.

João: 55 anos, natural do Rio de Janeiro, HIV há 15 anos. Não houve relatos sobre religiosidade em sua fala.

Gisela: 45 anos, natural do Rio de Janeiro, HIV há 11 anos. Referiu ser cristã, porém não determinou religião específica.

Eduardo: 60 anos, natural do Rio de Janeiro, diagnóstico de HIV há cinco anos. Seus relatos demonstram certa religiosidade, porém não se declarou praticante de nenhuma religião específica.

\section{Conteúdos religiosos nas falas livres dos sujeitos}

Das nove entrevistas realizadas, em três não houve relatos espontâneos sobre religiosidade ou espiritualidade, sendo estas as entrevistas de André, João e Rosane.

Nas demais entrevistas, os relatos sobre religiosidade surgiram com base em duas categorias: a primeira, que relaciona a religiosidade como fortalecimento subjetivo no enfrentamento da fragilidade do adoecer, e a segunda, que aborda a função social da religião nas vidas destes indivíduos.

A seguir, descrevo os sentidos como estas categorias se apresentam nas narrativas dos sujeitos.

\section{O papel da religiosidade nas experiências subjetivas de enfrentamento}

Em algumas falas, verificou-se que a religiosidade foi utilizada como forma de fortalecimento do indivíduo no enfrentamento das fragilidades que o HIV expõe. Neste contexto, as falas trazem conteúdo de explicação do infortúnio, de expiação da culpa do contágio e de deslocamento dos valores morais negativos que as pessoas vivem devido ao HIV.

A entrevista de Carolina exemplifica bem estes aspectos subjetivos, pois sua narrativa é carregada de culpa em relação ao contágio pelo HIV. No início da entrevista, relata ser evangélica praticante e declara que seu problema tinha surgido num período da vida em que ainda não tinha se convertido: "Meu problema foi lá atrás, antes de eu conhecer Jesus". Devido a sua conversão à igreja, Carolina mantinha uma fé de que seu problema poderia ser resolvido, inclusive relata um momento em que chegou a parar de tomar remédios, pois acreditava numa cura divina: "Voltei (da internação) muito revoltada: eu não tenho nada não, eu não aceito, Deus não vai fazer isso comigo, e parei de tomar remédios pelo o que eu ouvia na igreja".

$\mathrm{Na}$ história de Renato, que se declara espírita praticante, ele coloca a religião e a oportunidade de frequentar o centro como uma fonte de força para seu fortalecimento pessoal:

"O centro é um lugar onde eu tenho muita força. Acho que a vida espiritual da gente, eu sempre fui espírita, acho que faz parte igual uma comida, tem que ter uma parte espiritual, uma igreja, qualquer lugar. O centro espírita assim me dá a maior força, eu sinto uma energia positiva boa."

No relato de Fernando, que se diz espírita não praticante, a crença nessa religião foi importante para aceitar a própria sexualidade, mais até do que o adoecimento, ajudando-o a aumentar a resiliência no enfrentamento da doença:

"A gente não pede para nascer assim (homossexual), que era um destino, porque se a gente já nasce assim, é coisa de Deus, a gente tem que ser o que é, tem que lutar para ter sua vida... eu sou guerreiro, eu vou lutar". 
Nesta fala é interessante notar a percepção da religião espírita como auxiliar do autorreconhecimento, por fornecer formas de explicar o sofrimento ou o comportamento e reduzir a culpa que é imputada a quem adoece. Aceitar sua condição, seu comportamento e sua doença podem ser parte de um processo que também inclui a construção de novas identidades, como, por exemplo, ser incluído como parte da identidade de um grupo religioso.

O espiritismo kardecista atribui uma conotação diferente daquela partilhada pelos evangélicos pentecostais e neopentecostais, tanto para as questões relacionadas à sexualidade quanto para a vivência com o HIV. A discriminação não faz parte dos preceitos religiosos, estando a doença associada aos karmas decorrentes de encarnações passadas, em que a cura dependerá, em primeiro lugar, da vontade divina - no sentido de aquela pessoa merecê-la ou não -, do aceite da condição kármica e do trabalho interior de transformação pessoal, fundamentado no livre-arbítrio (Cavalcanti, 1983). É nesse sentido que os dois espíritas praticantes - Fernando e Renato - encontraram acolhimento e conforto na frequência ao centro espírita, e fonte de força para o fortalecimento pessoal, tanto em termos do enfrentamento da doença quanto do aceite da opção sexual.

Para Gisela, a vivência da religiosidade reflete um enfrentamento muito pessoal dos males que a afligem. Não se declara pertencente a nenhuma religião, e nem compartilha rituais religiosos. A religiosidade tem um papel de fortalecimento dentro de sua vida, e sua visão de Deus é de um provedor de forças para que ela possa aguentar as dificuldades. " $E$, por mim mesmo, fui depositando algo muito forte dentro de mim, pedindo a Deus que, se fosse para eu ficar sofrendo em cima de uma cama, que ele me levasse, que eu não ia aguentar... No momento eu sou cristã, não estou em nenhuma igreja. Acredito em Deus, sempre acreditei, porque Ele é tudo na minha vida e não fosse Ele eu não estaria aqui hoje. Mas é aquele negócio, Deus não dá o cobertor se você não tiver sentindo frio, né, então este problema para mim eu vou sair dele".

Eduardo não faz referência a uma vivência religiosa estrita, porém reflete sobre a importância de crer em alguma coisa para seu fortalecimento pessoal. A sua vivência da religiosidade é individual e solitária, sem se colocar pertencente a nenhuma religião específica.

\footnotetext{
"Creio muito em Deus. Agradeço muito a Deus todo dia, dentro de minhas palavras, e peço muito por mim e por meus filhos. Eu tenho um irmão que é crente e que fica querendo me converter, mas eu tô satisfeito com Deus e acredito que Ele é um só, e lá dentro da minha casa, no meu quarto, eu oro e agradeço todo dia".
}

Gisela e Eduardo fazem parte do grupo denominado "sem religião", segundo terminologia do IBGE. De acordo com o Censo 2000, esse grupo passou de 4,8\% para 7,3\% da população brasileira - um crescimento bastante significativo. Entretanto é interessante observar que, deste percentual de indivíduos que se consideram sem religião, apenas 0,5\% não acreditam em Deus, isto é, são ateus (Camurça, 2006). Todos os outros acreditam em Deus, valorizam a experiência religiosa em suas vidas, mas não se identificam com nenhuma religião específica (Vasconcelos, 2006). Isto expressa, portanto, a desfiliação dos indivíduos das instituições religiosas e a opção por uma religiosidade própria. A não-aderência a uma religião específica não corresponde, necessariamente, a uma diminuição da importância da religião na vida dos indivíduos, pelo contrário, pode significar um compromisso com a sua própria religiosidade e crença ainda mais vigoroso; como demonstram os depoimentos de Gisela: "Deus é tudo na minha vida", e de Eduardo, que crê na existência de um único Deus, fundamental para o seu fortalecimento pessoal.

As narrativas trazidas por este grupo abordam a ideia da força emanante destas experiências subjetivas relativas à religiosidade, no sentido de apresentarem temáticas que percorrem da explicação do adoecimento, à esperança, ao conforto e à perseverança, os quais mostram-se como auxiliares no enfrentamento das dúvidas e dos sofrimentos causados pelo adoecimento. 


\section{A religiosidade na construção de laços e reconhecimento social}

Nesta categoria, observamos que a relação das pessoas com a religiosidade, com os aspectos morais compartilhados entre os membros das igrejas e com as relações sociais nas comunidades religiosas podem trazer aspectos motivadores ou desmotivadores em relação ao enfrentamento do adoecimento. Neste sentido, observaram-se falas que apontam para a vivência da religião numa expectativa de acolhimento ou não-acolhimento com as repercussões destas situações. Assim, a experiência religiosa pode estar incorporada na perspectiva do apoio, ou não, ao enfrentamento dos aspectos morais e afetivos e das repercussões clínicas do adoecimento pelo HIV.

Nos relatos de Carolina, pôde-se observar como ela estabelece a diferença entre a religiosidade (expressa pela fé e na perseverança em sua crença) e a dimensão social e institucional da igreja. Ela, apesar de reafirmar repetidamente sua fé, relata sua decepção ao perceber a falta de apoio de sua comunidade religiosa no momento que se encontrava fragilizada - física e moralmente - pela doença.

Demonstra esta frustração afirmando: “... Fui na igreja e também ninguém fez nada para me ajudar". Ela, portanto, demonstra que, apesar da decepção com a igreja como grupo social, manteve sua fé presente, de maneira a se fortalecer:

"A igreja, depois que eu tive este problema, não me apoiaram, não me acolheram, não corresponderam às minhas necessidades. A minha idéia era: larguei o rapaz, a bebida, larguei tudo por Jesus, porque então ele ia tirar minha vida agora? Eu acreditava que só minha fé ia me salvar".

A falta de apoio da comunidade religiosa neopentecostal diante da doença de Carolina pode ser compreendida dentro do contexto de explicação da doença, presente nessas religiões. Elas compreendem estas doenças como sendo fruto da ação maléfica dos demônios que se alojam no corpo do sofredor e que devem ser expulsos por meio de orações e práticas rituais de desobsessão (Rabelo, 1993).

No caso do adoecimento pela AIDS, a discriminação moral, devido ao fato de ser uma infecção sexualmente transmissível, pode ser uma questão importante na relação de Carolina com os membros da comunidade religiosa. O dualismo entre bem e mal, pecado e virtude, pode influir na forma de interpretação e na aceitação moral e social de Carolina pelo grupo, uma vez que a sexualidade, para os neopentecostais, deve ser vivida unicamente no âmbito do casamento heterossexual, e este deve ser priorizado para que seja efetivado apenas entre os membros da comunidade religiosa.

Edivaldo também teve um distanciamento de sua comunidade religiosa, no seu caso, por exercer uma função hierárquica (pai de santo) e não se achar competente para continuar nesta função, o que causou transtornos emocionais e sociais significativos:

"Justamente por eu ter essa quantidade de amizade e ter esta vida espiritual, eu tive que esconder isso de muita gente, como escondo até hoje [...]. Ter que conviver com isso é muito difícil, é dormir e não saber se vai acordar."

Sua fala expressa o sentimento de desvalor por se sentir impedido de exercer sua mediunidade. No caso dele, a mediunidade, além de fazer parte de sua identidade cultural e religiosa, está associada a um valor social, a uma identidade de destaque em sua comunidade. Esta situação traz para ele repercussões afetivas e morais negativas associadas ao fato de estar doente, por uma doença como a AIDS:

“Não, não consegui ainda (voltar a ter uma vida normal), mas assim tudo você tem que inventar desculpas já que você não quer contar nada para ninguém. Eu não quero me expor, porque sei que as pessoas ainda são podres, infelizmente, porque se filho de santo (os freqüentadores do terreiro), não sei se você entende isso, se ele souber de uma coisa dessa, ele sai da sua casa e não quer mais ficar porque ele acha que você não tem mais possibilidade de poder passar (o passe)". 
Em sua história, a doença foi a causa de seu afastamento das atividades religiosas, o que dificultou mais ainda a adaptação à nova realidade de vida: "Eu cheguei um ponto que eu queria desistir de até viver, porque eu vivi quase 8 meses escondido, eu não queria que ninguém visse o estado que eu estava".

O fato de ter se afastado de seus deveres religiosos é muito marcante em sua fala, trazendo conteúdo de sofrimento e pesar. A decisão de distanciar-se de sua religião - a umbanda - foi estritamente de cunho pessoal, e não decorrente dos preceitos religiosos, uma vez que, de modo geral, essa religião não costuma discriminar seus fiéis devido às suas opções sexuais e nem em função das doenças que recaem sobre eles (Montero, 1985). Edivaldo, por exercer a autoridade máxima em seu grupo religioso, não se sentiu suficientemente forte - moral e psiquicamente - para enfrentar as possíveis discriminações que sofreria, uma vez que tem consciência do estigma da doença e do estágio de "podridão" da humanidade, como ele próprio fez referência em seu depoimento. Tal visão do estigma, construído através da percepção social introjetada na vivência pessoal, é capaz de ser transformadora de costumes e hábitos pessoais ao longo da convivência com o adoecimento (Parker, Aggleton, 2003).

Renato, por sua vez, já tem uma experiência, no centro espírita do qual participa, que é diferente da vivida por Edivaldo. Renato relata ter encontrado acolhimento e conforto para lidar com seu adoecimento: "Foi na minha religião que eu tive mais apoio. Na minha família ninguém sabe não. Eu tenho amigos espirituais, do centro espírita". Sua religiosidade o faz enxergar o adoecimento de uma forma em que não há espaço para revolta. Dividir bons sentimentos com os companheiros do centro fortalece-o para o enfrentamento do cotidiano.

\section{A influência da religiosidade no processo de enfrentamento do adoecimento por HIV}

A relação entre o adoecimento pelo HIV e a religiosidade foi estudada por Faria e Seidl (2006), que reafirmaram o resultado de outros estudos que apresentam a importância da religiosidade no aumento de autonomia e suporte social dos indivíduos. Tsevat et al. (2009) acompanharam mais de trezentos pacientes que contraíram o vírus, durante uma média de 15 meses, e obtiveram resultados que demonstraram aumento da vivência religiosa em seus vários aspectos, desde vivências íntimas e pessoais até participação coletiva em cultos, o que demonstrou aumento da qualidade de vida destas pessoas devido a maior vivência e apoio num grupo social. Tal resultado também foi achado em estudo semelhante de Ironson et al. (2006), assim como Cotton et al. (2006), que descrevem o aumento de otimismo, autoestima, satisfação e, mesmo, redução do uso de bebidas alcoólicas em pacientes soropositivos que têm uma relação positiva e ativa da religião em suas vidas.

Os relatos dos entrevistados trouxeram narrativas de enfrentamento, que, de acordo com Folkman et al. (1986, p.572), são "os esforços cognitivos e comportamentais voltados para o manejo de exigências ou demandas internas ou externas que são avaliadas como sobrecarga aos recursos pessoais". A avaliação de Pargament et al. (2001) em relação às religiões é compatível com o que observamos entre os entrevistados, isto é, a possibilidade de desenvolvimento de comportamentos positivos e negativos em relação aos enfrentamentos religiosos no campo da saúde. Características positivas seriam as que levam a um apoio espiritual, perdão religioso, participação religiosa colaborativa, ligação social e redefinição benevolente do estressor. Características negativas são: o descontentamento religioso, presença de conflitos interpessoais com membros do grupo religioso e dúvidas sobre o poder de Deus para interferir no problema em questão.

Nos relatos anteriores, existem falas que exemplificam tais características. Carolina, após o diagnóstico, viveu momentos de isolamento e descontentamento dentro de seu grupo religioso, no qual se pode observar um enfrentamento negativo; porém, num movimento contrário, ela resgata suas possibilidades de ligações diretas com Deus, sem intermediários, para se fortalecer, retornando a um enfrentamento positivo que se assemelha ao observado por Faria e Seidl (2006) em pacientes com HIV.

Gisela, por sua vez, relata viver momentos pendulares que oscilam entre entregar tudo na mão de Deus, ou depender apenas de seu esforço próprio. Este movimento dual foi estudado por Jenkins (1995) com pacientes com diagnóstico de HIV, quando ele também observou tais movimentos de idas e vindas entre a crença como possibilidade espiritual de força e a vivência da força pessoal como elemento indispensável no bem-estar. 
A religião é comumente apontada como uma fonte de suporte e integração social (Valla, 2006). Nos relatos de Renato e Edivaldo, pôde-se observar a diversidade e importância da experiência religiosa em suas vivências. Renato teve todo suporte em seu centro espírita, sentindo-se plenamente acolhido em suas necessidades sociais; já Edivaldo perdeu seu suporte e apoio ao ter de se afastar de sua religião devido à doença.

A AIDS representa, no meio social, uma série de metáforas depreciativas, tais como as associadas a castigo, punição, que seriam a condenação sobre os comportamentos socialmente reprovados (Kopelman, 2002; Sontag, 1989). Soma-se a esta visão socialmente estabelecida, uma outra de cunho religioso, tradicionalmente católica e pentecostal, de decadência moral do individuo devido à culpa por seus comportamentos mundanos (Kopelman, 2002). Fernando traz, em sua história, esta carga de culpa e preconceito em sua vivência da homossexualidade, a qual se agrega à doença. Entretanto, a vivência religiosa espírita foi capaz de trazer alento para sua angústia.

Uma questão central para o campo da atenção aos portadores de AIDS, observada neste estudo, foi a constatação de os relatos da religiosidade não se contraporem ao tratamento médico farmacológico. Pinho (2010) demonstra essa relação harmônica que pode acontecer entre os itinerários religiosos e os da biomedicina nas pessoas que convivem com HIV, construindo um enfrentamento positivo do adoecimento.

De maneira geral, o que se pode notar é que, apesar da desordem e desestruturação que o diagnóstico de HIV causa na vida das pessoas que são suas portadoras, elas são capazes de criar mecanismos de fortalecimento da personalidade às adversidades causadas pela doença (Favoreto, Ferreira, 2009). Nesta perspectiva, a religião é um caminho que favorece, por sua característica de ajudar a ressignificar a vida, colocar ordem à desordem que é abruptamente trazida pela doença (Pinho, 2010).

\section{Conclusão}

Este trabalho vem fortalecer as discussões sobre a importância do campo da religiosidade na vivência dos adoecimentos crônicos, focando, de modo particular, os portadores de HIV. O fato de essa análise ter sido realizada com base em um material empírico (entrevistas) que não foi originalmente desenhado para aprofundar e especificar o tema da religiosidade traz, com certeza, algumas limitações. Contudo, a análise deste tema, em narrativas sobre o adoecimento pela Aids e seus enfrentamentos, aponta a relevância que ele tem nas estórias de vida e adoecimento, assim como nos leva a chamar a atenção dos profissionais de saúde para estas questões.

Vasconcelos (2006) discute a importância deste tema no trabalho em saúde de maneira geral, argumentando a necessidade de se ter uma formação profissional capacitada para acolher tal escuta. É claro, nesta discussão, que trabalhar com a religiosidade no campo da saúde é posterior à necessidade da escuta ativa e qualificada das demandas das pessoas. Para isto, é imprescindível a construção de um vínculo terapêutico eficaz.

$\mathrm{Na}$ construção do enfrentamento do adoecimento pelo HIV - doença ainda hoje orbitada por questões morais, como preconceitos, estigmas em relação ao gênero e à infecção, assim como sociais, como dificuldades de inserção no trabalho ou em grupos específicos, como, também, dificuldades econômicas e pessoais - se faz necessário um olhar cada vez mais amplo. Neste contexto, a religiosidade se faz presente, por se tratar de uma estrutura moral (subjetivamente construída) e social (culturalmente construída).

Assim, atentar para as narrativas das pessoas que buscam os profissionais de saúde é estar aberto para todas as possibilidades dos campos biopsicossociais que podem emergir em suas falas, sendo a religiosidade uma delas. Cabe aos profissionais procurarem entender como a religiosidade pode surgir de maneira positiva ou negativa na vivência do adoecimento, tentando acolher as angústias dos usuários, de modo a auxiliá-los na busca de autonomia.

Existem várias maneiras de se abordarem estas questões religiosas, que vão desde a escuta ativa, quando o tema emergir espontaneamente, como foi o caso deste estudo, até abarcar a possibilidade 
que uma abordagem religiosa seja incluída nas entrevistas clínicas, nos grupos de apoio e, sobretudo, que ela não seja encarada com preconceito ou com prejulgamentos pelos profissionais de saúde.

Dessa forma, o profissional deve procurar fazer um deslocamento de seus próprios valores religiosos para poder compreender os valores de seus pacientes e as influências da religiosidade no processo terapêutico, assim como estar aberto para discuti-las com o paciente.

Afinal, a doença, representada como desordem do cotidiano (Montero, 1985), tem, em cada sujeito, seus caminhos de reconstrução e adaptação, e nós, enquanto profissionais, devemos buscar compreender e respeitar a importância destes caminhos individuais, e, sobretudo, estarmos preparados para auxiliar quando for possível.

\section{Colaboradores}

Débora Carvalho Ferreira e Cesar Augusto Orazem Favoreto responsabilizaram-se pela coleta dos dados (entrevistas), análise e discussão. Maria Beatriz Lisbôa Guimarães participou da discussão e revisão final.

\section{Referências}

AYLE, H. et al. Religious activity improves life satisfaction for some physicians and older patients. J. Am. Geriatr. Soc., v.47, n.4, p.453-5, 1999.

BRIEN, K.K. et al. Exploring disability from the perspective of adults living with HIV/Aids: Development of a conceptual framework. Health Qual. Life Outcomes, v.6, n.76, 2008. Disponível em: http://www.biomedcentral.com/1477-7525/6/76.

BROCKMEIER, J.; HARRÉ, R. Narrativa: problemas e promessas de um paradigma alternativo. Psicol.: Refl. Crít., v.16, n.3, p.525-35, 2003.

BUSSING, A. et al. Are spirituality and religiosity resources for patients with chronic pain conditions? Pain Med., v.10, n.2, p.327-39, 2009.

CAMURÇA, M. A realidade das religiões no Brasil no Censo do IBGE-2000. In: TEIXEIRA, F.; MENEZES, R. (Orgs.). As religiões no Brasil. Petrópolis: Vozes, 2006. p.35-48.

CAVALCANTI, M.L.V.C. O mundo invisível: cosmologia, sistema ritual e noção de pessoa no Espiritismo. Rio de Janeiro: Zahar Editores, 1983.

COTTON, S. et al. Spirituality and religion in patients with HIV/AIDS. J. Gen. Int. Med., v.21, supl.5, p.5-13, 2006.

CUNHA, C.C.; CZERESNIA, D. O direito à saúde e as peculiaridades do cuidado: uma perspectiva do tratamento das pessoas com HIV/Aids. In: Ministério da Saúde; Fundação Oswaldo Cruz; Núcleo de Estudos Em Direitos Humanos e Saúde Helena Besserman.

Saúde e direitos humanos, v.2, n.2, p.46-54, 2005.

DANIEL, H.; PARKER, R. Aids, a terceira epidemia. Rio de Janeiro: Iglu Editora, 1990.

ELLISON, C.G. Religious involvement and subjectices well being. J. Health Soc. Behar., v.32, n.1, p.80-99, 1991.

FARIA, J.B.; SEIDL, E.M.F. Religiosidade, enfrentamento e bem-estar subjetivo em pessoas vivendo com HIV/Aids. Psicol. Estud., v.11, n.1, p.155-64, 2006.

FAVORETO, C.A.O.; FERREIRA, D.C. Processo clínico terapêutico e as mediações entre sujeitos do cuidado: afinal, de qual protagonista estamos falando? In: PINHEIRO, R.; 
MARTINS, P.H. (Orgs.). Avaliação em saúde na perspectiva do usuário: abordagem multicêntrica. Rio de Janeiro: Cepesc, IMS/UERJ, Ed. Universitária UFPE, Abrasco, 2009. p.333-46.

FERRARO, K.F.; ALBRECHT-JENSEN, C.M. Does religion influence adult health? J. Sci. Study. Relig., v.30, n.2, p.193-302, 1991.

FOLKMAN, S. et al. Appraisal, coping, health status and psychological symptoms. J. Person. Soc. Psychol., v.50, n.4, p.571-9, 1986.

FREITAS, M.C.; MENDES, M.M.R. Condição crônica: análise do conceito no contexto da saúde do adulto. Rev. Latino-Am. Enferm., v.15, n.4, p.590-7, 2007.

GUIMARÃES, H.P.; AVEZUM, A. O impacto da espiritualidade na saúde física. Rev. Psiq. Clín., v.34, supl.1, p.88-94, 2007.

IRONSON, G.; STUETZLE, R.; HETCHER, M.A. An increase in religiousness/spirituality occurs after HIV diagnosis and predicts slower disease progression over 4 year in people with HIV. J. Gen. Intern. Med., v.26, supl.5, p.62-8, 2006.

JENKINS, S. Religion and HIV: implications for research and intervention. J. Soc. Issue, v.51, n.2, p.131-44, 1995.

KOPELMAN, L.M. If HIV/AIDS is punishment, who is bad? J. Med. Philos., v.27, n.2, p.231-43, 2002.

LEVIN, J.; SCHILLER, P. Is there a religious factor in health? J. Relig. Health, v.26, n.1, p.9-36, 1987.

MELCHIOR, R. et al. Desafios da adesão ao tratamento de pessoas vivendo com HIV/Aids no Brasil. Rev. Saude Publica, v.41, supl.2, p.87-93, 2007.

MINAYO, M.C.S. O desafio do conhecimento: pesquisa qualitativa em saúde. 3.ed. São Paulo: Hucitec, 1994.

MONTERO, P. Da doença à desordem. Rio de Janeiro: Graal, 1985.

PAIVA, V. Sem mágicas soluções: a prevenção e o cuidado em HIV/Aids e o processo de emancipação psicossocial. Interface - Comunic., Saude Educ., v.6, n.11, p.25-38, 2002.

PARGAMENT, K.L. et al. Religious coping among the religious: the relationships between religious coping and well-being in a national sample of Presbyterian clergy, elders and member. J. Sci. Study Relig., v.40, n.3, p.491-513, 2001.

PARKER, R.; AGLLETON, P. HIV and Aids-related stigma and discrimination: a conceptual framework and implications for action. Soc. Sci. Med., v.57, n.1, p.13-24, 2003.

PERES, M.F.P. et al. A importância da espiritualidade e da religiosidade no manejo da dor e dos cuidados paliativos. Rev. Psiquiatr. Clín., v.34, supl.1, p.82-7, 2007.

PINHO, P.A. Itinerários terapêuticos em construção: Aids, biomedicina e religião. 2010. Dissertação (Mestrado) - Departamento de Medicina Preventiva, Universidade Federal de São Paulo, São Paulo. 2010.

RABELO, M.C. Religião e cura: algumas reflexões sobre a experiência religiosa das classes populares urbanas. Cad. Saude Publica, v.9, n.3, p.316-325, 1993.

SCHAURICK, D.; COELHO, D.F.; MOTTA, M.G.C. A cronicidade no processo saúdedoença: repensando a epidemia da Aids após os anti-retrovirais. Rev. Enferm. UERJ, v.14, n.3, p.455-62, 2006.

SILVA, A.L.C.; WAIDMAN, M.A.P.; MARCON, S.S. Adesão e não-adesão à terapia anti-retroviral: as duas faces de uma mesma vivência. Rev. Bras. Enferm., v.62, n.2, p.213-20, 2009.

SILVA, G.A. Da aparência a essência: o cuidado no cotidiano do portador do HIV. Juiz de Fora: Editora da UFJF, 2004. 
SILVA, L.M.S. et al. Integralidade em saúde: avaliando a articulação e a coresponsabilidade entre o Programa Saúde da Família e um serviço de referência em HIV/ Aids. Epidemiol. Serv. Saude, v.14, n.2, p.97-104, 2005.

SONTAG, S. A Aids e suas metáforas. São Paulo: Companhia das Letras, 1989.

TSEVAT, J. et al. Change in quality of life after being diagnosed with HIV: a multicenter longitudinal study. Aids Pat. Care STDs, v.23, n.11, p.931-7, 2009.

VALLA, V.V. A vida religiosa como estratégia das classes populares na América Latina de superação da situação do impasse que marca suas vidas. In: VASCONCELOS, E.M. (Org.). A espiritualidade no trabalho em saúde. Rio de Janeiro: Hucitec, 2006. p.265-95.

VASCONCELOS, E.M. A espiritualidade no cuidado e na educação em saúde. In: VASCONCELOS, E.M. (Org.). A espiritualidade no trabalho em saúde. Rio de Janeiro: Hucitec, 2006. p.13-153.

FERREIRA, D.C.; FAVORETO, C.A.O.; GUIMARÃES, M.B.L. La influencia de la religiosidad en los que viven con el VIH. Interface - Comunic., Saude, Educ., v.16, n.41, p.383-93, jan./mar. 2012.

Este artículo analiza la correlación entre salud y espiritualidad en la enfermedad crónica, tratando de entender cómo las personas buscan ayuda para fortalecer frente a las dificultades de la enfermedad. El objetivo fue discutir temas de la religión que surgieron en el discurso de las personas que viven con el HIV. Basado en el relato de estos sujetos, se analizaron el informe sobre la religiosidad y su influencia en el proceso salud-enfermedad. Hemos observado algunas relaciones que apuntan afrontamientos religiosos positivos y / o negativos durante la enfermedad, cambios en el pensamiento y la importancia de la experiencia religiosa en cómo los individuos desarrollan sus relatos. Hay necesidad de que los profesionales de salud estén atentos a la aparición de dichos contenidos, ya que traen aspectos sobre cuestiones terapéuticas tales como cooperación, apoyo social, conflictos y singularidades individuales que pueden ayudar en el proceso de lucha contra la enfermedad.

Palabras clave: Enfermedad crónica. VIH. Religión. Narrativa. 
